\title{
A CIÊNCIA ABERTA E OS DIREITOS DE PROPRIEDADE INTELECTUAL: UM OLHAR A PARTIR DA ECONOMIA CRIATIVA E DA CIÊNCIA DO COMMONS
}

\section{OPEN SCIENCE AND INTELLECTUAL PROPERTY RIGHTS: AN INSIGHT AT THE CREATIVE ECONOMY AND THE SCIENCE OF COMMONS}

\author{
Adriana Carla Silva de Oliveira ${ }^{1}$ \\ Patrícia Borba Vilar Guimarães ${ }^{2}$ \\ Débora Costa Araújo Di Giacomo Koshiyama ${ }^{3}$
}

\section{Resumo}

O estudo é resultante de uma tese de doutoramento que versa pela Ciência Aberta e pelos Direitos de Propriedade Intelectual na contemporaneidade. Os Direitos de Propriedade Intelectual vigentes no paradigma proprietário econômico são refletidos para a ambiência da ciência aberta. O estudo é inovador e objetiva refletir os direitos de propriedade intelectual à luz da Economia Criativa e da Ciência do Commons. Os dados de pesquisa oriundos da pesquisa aberta são compreendidos como bens intelectuais comuns. Teoricamente, o estudo está substanciado pelas seis dimensões (epistemológica, teórica, técnica, morfológica, política e ética) do estudo de Bufrem. É predominantemente qualitativa e adotou a multidisciplinaridade para as conexões temáticas que substanciam o estudo. Por fim, observa-se que a ciência aberta

\footnotetext{
${ }^{1}$ Pós-doutoranda em Direito pela Universidade Federal do Rio Grande do Norte (2017- ). Doutora em Ciência da Informação pela Universidade Federal da Paraíba (2016). Visiting Scholar PhD no College Communication \& Information na School Information Science pela University of Tennessee, Knoxville, Estados Unidos (2015). Mestre em Engenharia de Produção pela Universidade Federal do Rio Grande do Norte (2004). Especialista em Gestão Estratégica de Empresas (2002). Graduada em Direito pela Universidade Potiguar (2010). Bacharel em Biblioteconomia pela Universidade Federal da Paraíba (1992). Analista Judiciário do Núcleo de Assessoria Especial à Presidência do Tribunal de Justiça do Rio Grande do Norte. E-mail: adrianacarla.a@gmail.com

2 Bacharel em Direito pela Universidade Estadual da Paraíba (1997). Tecnóloga em Processamento de Dados pela Universidade Federal da Paraíba (1989); Mestre em Direito pela Universidade Federal do Rio Grande do Norte (2008). Mestre pelo Programa Interdisciplinar em Ciências da Sociedade, na área de Políticas Sociais, Conflito e Regulação Social, pela Universidade Estadual da Paraíba (2002). Doutora em Recursos Naturais pela Universidade Federal de Campina Grande (2010). É Advogada e Professora da Universidade Federal do Rio Grande do Norte, no Departamento de Direito Processual e Propedêutica (DEPRO). E-mail: patriciaborb@gmail.com

${ }^{3}$ Graduação em Biblioteconomia pela Universidade Federal do Rio Grande do Norte (2004). Atualmente é bibliotecária-documentalista da Universidade Federal do Rio Grande do Norte. Tem experiência na área de Desenho Industrial, com ênfase em Desenho Industrial, atuando principalmente nos seguintes temas: design, design centrado no usuário, repositório institucional, divulgação científica e usabilidade. E-mail: deborakoshiyama@gmail.com
} 
é um potencial inovador das práticas científicas modernas. Os dados de pesquisa oriundos da investigação científica são bens intelectuais comuns e, portanto, são de acesso aberto, público e gratuito. Direcionam assim, os direitos de propriedade intelectual para novas formas de recompensa autoral, por meio da atribuição e citação. Conclui-se que há uma necessidade de promoção da ciência aberta, na perspectiva de superar a proprietização dos bens intelectuais, baseada no modelo econômico tradicional vigente, para um ambiente aberto, colaborativo e compartilhado à luz do paradigma do Commons.

Palavras-chave: Direitos de Propriedade Intelectual, Ciência Aberta, Economia Criativa, Ciência do Commons, Bens Intelectuais.

\section{Abstract}

The study is the result of a doctoral thesis that deals with open science and Intellectual Property Rights. The Intellectual Property Rights in the economic proprietary paradigm are reflected in the open science environment. The study is innovative and aims to reflect intellectual property rights in light of the Creative Economy and Commons Science. Research data from open research is understood as common intellectual property. Theoretically, the study is substantiated by the six dimensions (epistemological, theoretical, technical, morphological, political and ethical) of the study of Bufrem. It is predominantly qualitative and adopts the multidisciplinarity for the thematic connections that substantiate the study. Finally, it is observed that open science is an innovative potential of modern scientific practices. Research data from scientific research are common intellectual property and therefore are open, public and free. They thus direct intellectual property rights to new forms of authorial reward, through attribution and quotation. It is concluded that there is a need to promote open science, in order to overcome the propertyzation of intellectual property, based on the current traditional economic model, for an open, collaborative and shared environment in the light of the Commons paradigm.

Keywords: Intellectual Property Rights, Open Science, Creative Economics, Commons Science, Intellectual Property. 


\section{INTRODUÇÃO}

Os Direitos de Propriedade Intelectual (DPIs) vigentes na publicação científica precisam ser repensados e compreendidos para uma sociedade que possui características que enfatizam a globalização, o compartilhamento, a colaboração e o ambiente digital. Esse repensar é guiado pelo quarto paradigma científico, que apregoa um novo fazer científico no cenário da ciência contemporânea e conduz a investigação científica aberta e pública.

Para a condução do artigo em tela, dois direcionamentos foram definidos. O primeiro direciona à compreensão da ciência tradicional para o prisma da ciência do commons. A ciência do commons é baseada no commons paradigm. Esse paradigma apregoa a colaboração e a coletividade e preconiza como constructo os bens intelectuais. Tais bens são advindos de práticas coletivas, colaborativas e de cocriações, representadas em ambientes de pesquisa e inovação aberta, a exemplo das produções peer-to-peer, wiki e crowdsourcing (KROKOSCZ, 2015; ALBAGLI, 2015).

No escopo da ciência do commons os bens intelectuais são gerados através de processos intelectuais, criativos, científicos ou culturais, que transformam-se em informação e conhecimento. Atualmente, os bens intelectuais englobam também dados de pesquisa oriundos dos processos de investigações científicas desde a concepção da pesquisa.

O segundo direcionamento está associado ao paradigma econômico vigente nos direitos de propriedade intelectual. A ideia de propriedade, exclusivista e individualista - vigente nos sistemas autorais - expande para o pensar da autoria em um ambiente de colaboração compartilhado e para direitos coletivos, pressupõe uma nova acepção para as questões autorais - a autoria colaborativa.

Esses direcionamentos são apoiados por duas abordagens no âmbito deste estudo. A abordagem multidimensional direcionada ao contexto da ciência contemporânea. Fundamentase metodologicamente nos estudos de Bufrem (2013) e de Gray (2007) que propõem a pesquisa científica em diferentes dimensões e a adoção de dados de pesquisa como matéria prima, respectivamente. No que tange à adoção de dados como produto primário em ambientes de pesquisa é apoiada epistemologicamente pelo quarto paradigma científico.

Enquanto que, a abordagem multidisciplinar permite compreender interseções entre diferentes disciplinas do saber. No estudo em tela a multidisciplinaridade está relacionada como a Ciência da Informação e as Ciências Jurídicas, e é transversalmente apoiada pela Economia. A transversalidade com a Economia está sob a ótica da Teoria do Commons e da Economia 
Criativa. A EC enfatiza ambientes de criação, inovação e criatividade, gerando bens intelectuais. Os bens intelectuais na perspectiva da Teoria do Commons são entendidos como bens comuns, e por conseguinte, são públicos, gratuitos e abertos. Assim, pensar os dados de pesquisa à luz dos bens intelectuais e os direitos de propriedade intelectual sob a vertente do commons é o foco deste estudo.

Nesse diapasão, a problemática reflete questões relacionadas com mudanças nas práticas da comunicação científica e nos direitos de propriedade intelectual vigentes nos sistemas atuais. É sabido que por séculos as práticas científicas foram apoiadas pela cultura impressa, que tornavam públicos apenas os resultados finais da investigação científica. Recentemente, movimentos como o Open Access, Open Science e Open Data, estão provocando mudanças substanciais e paradigmáticas no fazer e publicar a ciência.

Consequentemente, outros aspectos relacionados com as práticas científicas também estão em mudanças, como por exemplo, os DPIs. Durante séculos os DPIs foram regidos por regulações e legislações apoiadas em sistemas privatísticos econômicos. Os sistemas autorais vigentes são teoricamente alicerçados em um paradigma que apregoa a propriedade e exclusividade. Esse é o paradigma proprietário econômico vigente.

Contudo, já se sabe que, "estamos no meio de uma transição para uma nova era científica, uma era comparável a da revolução científica do século XVII e a da transição para a Idade Moderna" (DELFANTI; PITRELLI, 2015, p. 59). Novas práticas científicas trazem a nova essência do modus operandi - fazer, compartilhar, divulgar, acessar, usar, reusar e reproduzir dados, informações, modelos e teorias. A natureza colaborativa, compartilhada e multidisciplinar corrobora com esse novo fazer científico. É portanto, a essência de uma ciência aberta, orientada para os dados de pesquisa.

Com o intuito de compreender a problemática que versa sobre os DPIs vigentes e a reflexão na perspectiva da ciência aberta, o estudo direciona a questão problema para a seguinte indagação: os Direitos de Propriedade Intelectual na atual Ciência Aberta estão refletidos à luz da Economia Criativa e da Teoria do Commons?

Para responder a essa indagação, a pesquisa objetiva refletir os Direitos de Propriedade Intelectual na perspectiva da Ciência Aberta, sob a ótica da Ciência do Commons e da Economia Criativa.

Metodologicamente, a pesquisa é qualitativa e está apoiada no estudo de Bufrem (2013). Esse estudo reflete a ciência contemporânea a partir de seis dimensões. A base epistemológica é alicerçada no método quadripolar, idealizado por Paul de Bruyne, J. Herman e 
M. de Schoutheete (1974). Com o aprimoramento do método, o estudo de Bufrem trouxe um modelo científico alternativo e multidimensional, utilizado para análises e discussões em diversas áreas das Ciências Sociais, ressaltando naturezas, gêneros e dimensões que são aplicáveis em diferentes pesquisas científicas.

A ideia de trazer a multidimensionalidade como parte do estudo tem o propósito de demonstrar que a ciência possui dimensões e pode ser entendida a partir de perspectivas diversas. Assim, para nortear esse estudo foram adotadas dimensões que abordam aspectos políticos, normativos, epistemológicos, teóricos, morfológicos, legais, éticos e culturais. Tais dimensões são vislumbradas para um ambiente colaborativo voltado para práticas científicas abertas e mudanças nos sistemas autorais vigentes. O estudo fez um recorte no contexto da comunicação científica, pensando transversalmente, os DPIs na Ciência Aberta, a luz da Ciência do Commons e da Economia Criativa. Além de refletir os dados de pesquisa como bens intelectuais e comuns no contexto científico contemporâneo.

\section{A CIÊNCIA DO COMMONS E A ECONOMIA CRIATIVA COMO LOCUS DA PROPRIEDADE INTELECTUAL}

As primeiras manifestações dos DPIs foram originadas na cultura ocidental durante os impérios grego e romano. Mas foi a partir do surgimento das 'prensas de tipos móveis', descoberta por Johannes Gutenberg (1450), as questões sobre a autoria e a Propriedade Intelectual efetivamente enfatizam os aspectos de individualidade, propriedade e exclusividade dos feitos intelectuais, que confrontam com a visão coletivista apregoada desde os primórdios.

A invenção de Gutenberg provocou a mudança no estado das coisas (EISENSTEIN, 1998). Os tipos móveis (prensa) de Gutenberg, oportunizaram a expansão em larga escala das produções intelectuais, aflorando assim, os questionamento acerca dos direitos autorais e as primeiras reivindicações pela proteção e remuneração autoral individual (MARTINS FILHO, 1998). Nessa época, os sistemas de propriedade intelectual foram condicionados a um regime de propriedade privada e exploração econômica - originado o paradigma proprietário econômico.

No contexto da pesquisa científica, a lógica capitalista foi incorporada e surgiram diferentes formas de registro e apropriação da produção intelectual. Os primeiros jornais científicos surgidos na França e Inglaterra em 1600, foram os responsáveis pelos primeiros registros iniciais do copyright. 
A preocupação obsessiva pela propriedade intelectual, desde a invenção da prensa, provocou o "alargamento dos mecanismos de apropriação privada da produção intelectual e cultural, ampliando e aprofundando relações capitalistas de mercado para áreas que até então constituíam uma reserva social" (ALBAGLI, 2015, p. 10). Tais mecanismos alicerçados no paradigma proprietário econômico e em relações capitalistas regulam a propriedade intelectual há séculos.

Contudo, as tendências contemporâneas apontam para uma cultura colaborativa, coletiva e compartilhada direcionada à ciência do comum, aberta e colaborativa. No âmbito legal, as legislações vigentes buscam o equilíbrio dos DPIs junto às novas formas de publicação científica. Nesse sentido, o movimento open access impulsionou o entrelaçamento dos modos de comunicação eletrônica com novas dimensões ao acesso à informação (BORGMAN, 2003).

Dessa forma, os sistemas de DPIs estão sendo repensados para atender as atuais dinâmicas da sociedade digital, sem perder de vista as iniciativas que impulsionam o desenvolvimento econômico, tecnológico, industrial, científico, técnico, cultural e social do país. Albagli (2015, p. 10) afirma que "os instrumentos de propriedade intelectual, em seu atual formato, já não cabem no novo paradigma"

Mudanças e interações almejadas para uma sociedade digital levantam as reflexões no arcabouço jurídico da propriedade intelectual, que por ora, já se apresenta ineficaz e não contempla as práticas emergentes de ambientes científicos, tecnológicos, sociais e culturais. "As novas formas de comunicação não cancelam o conceito de propriedade intelectual mas, ao contrário, estimulam o legislador a intervir para tutelar os direitos dos autores que fixam seus pensamentos em escritos divulgados pela rede [...]". (PAESANI, 2012, p. 2). Assim, grande desafio político-ético-legal está em conduzir uma agenda global para o entendimento de que a ciência aberta altera as práticas existentes na ciência tradicional e interfere nos mecanismos regulatórios dos DPIs que garantem a propriedade intelectual aos autores e inventores.

Assim, o estudo propõe duas interpelações acerca da transversalidade dos Direitos de Propriedade Intelectual vigentes e a ciência aberta. A primeira interpelação se manifesta nas dimensões político-legais, enfatizando os DPIs como subdomínio de uma política orientada aos dados de pesquisa. E a segunda, é a dimensão epistemológica, refletindo o objeto dos dados de pesquisa como bens intelectuais comuns, a partir da ótica da cultura do commons, para uma sociedade colaborativa, compartilhada, aberta e digital. 
A primeira interpelação preconiza que a ciência aberta constitui um locus de poder e negociação, contradições, ideologias, culturas, saberes e conhecimentos. As relações entre ciência-poder-saber são manifestadas em instâncias, dentro e fora do corpus institucional.

Os esforços da ciência aberta envolvem instâncias de "ação e decisão diferenciadas, internas e externas à ciência, que vão desde o pesquisador individual e equipes de pesquisa até o nível macro das políticas públicas e das regulações internacionais, passando pelo nível das instituições científicas e agências de fomento" (ALBAGLI, 2015, p. 21). O empreendimento político voltado para a ciência aberta faz uso de dados de pesquisa nas práticas científicas, considerando a existência de níveis hierárquicos e diferentes instâncias institucionais.

Ademais, aspectos culturais, éticos, ideológicos e formas de poder estão enraizados nos valores intrínsecos da nação ou de uma instituição. Pensar nesses valores no sentido stricto sensu é relacioná-los aos aspectos internos e institucionais (pessoas, instrumentos e processos). No sentido lato sensu se voltam para os aspectos externos, tal como a política governamental pública ou uma área do conhecimento.

Nessa direção, pensar nos sentidos stricto sensu e lato sensu é essencial na condução de políticas de informação. Por política de informação se entende o conjunto de leis, regulações e posições doutrinárias e outras tomadas de decisões e práticas com efeitos constitutivos em toda sociedade envolvendo a produção, processamento, fluxo, acesso e uso (BRAMAN, 2011). Analogamente, conjecturar uma política para a ciência aberta orientada aos dados de pesquisa, inclui todos esses elementos e se acrescentam aspectos de compartilhamento, colaboração, reuso e reprodutibilidade.

A política legitimada por autoridade governamental passa a ser compreendida e nomeada como uma política pública de informação. Expectativa semelhante deve ser direcionada à ciência aberta, norteando a elaboração da política pública orientada aos dados de pesquisa, ensejando uma nova constituição dos sistemas de DPIs como um subdomínio dessa política.

A dimensão político-legal que envolve os DPIs no limiar de uma ciência aberta precisa ser pensada como uma nova conjectura para adequações legais e contemplem aspectos colaborativos, coletivos, éticos e culturais. Deve auxiliar na compreensão das políticas e diretrizes que atentem para valores (extrínsecos e intrínsecos) que sustentem o amplo espectro da ciência aberta (MARQUES; PINHEIRO, 2013). Na dimensão política a predominância dos mecanismos de regulação dos mercados de informação, a exemplo da proteção dos dados é predominante. 
Nessa direção, a reflexão está no subdomínio dos DPIs relacionado com as interações colaborativas, mercados informacionais e culturais, além dos produtos intelectuais provenientes das instituições formais (universidades, indústrias e pesquisa), modelados na cultura do commons e do compartilhamento.

Isto posto, a segunda interpelação expõe o olhar multidimensional para a cultura do commons e da Economia Criativa. Compreender os dados de pesquisa numa perspectiva de bem comum e, por conseguinte, se constituir em um elemento de interesse da coletividade é merecedor de novas reflexões normativas e legais. Logo, é mister compreender essa perspectiva a partir da ótica do objeto de estudo (dados de pesquisa) na noção do commons. A ideia preliminar pressupõe que cultura, conhecimento e criatividade podem ser encapsuladas na noção da ciência aberta (FROSIO, 2014).

Na perspectiva do commons, os DPIs possuem conexão com a Economia, por meio da Teoria do Commons e da Economia Criativa. Afirma Albagli (2015) que a ciência aberta amplia o espectro de possibilidades e espaços de criação do saber quando ocorre uma interlocução da ciência com outros segmentos sociais e outros tipos de saberes.

Lafuente (2015) enfatiza essa perspectiva quando afirma que a 'ciência do comum' é sua própria condição. Defende que essa derivação deve ser um dos imperativos da nova gestão da ciência que rejeitam as regulações impostas pelos mecanismos econômicos da propriedade intelectual que transformam o conhecimento em informação codificada. A dinâmica tradicional, gera consequências devastadoras, quando há o incentivo de vários processos de privatização do conhecimento.

Assim, a noção de commons se apresenta em duas vertentes: a primeira relacionada com o entendimento de 'não propertising' e 'tragédia do commons'; e a segunda, com a ideia da Teoria do Commons e da Economia Criativa.

\section{REFLEXÃO ACERCA DOS DIREITOS DE PROPRIEDADE INTELECTUAL SOB A ÓTICA DA ECONOMIA CRIATIVA E DA CIÊNCIA DO COMMONS}

As mudanças atuais relacionadas com a ciência tradicional, reforça a necessidade de reflexão na práxis científica e nos aspectos relacionados com a propriedade intelectual. Nessa direção, o estudo foi conduzido por duas vertentes. A primeira vertente está direcionada à conceituação dos termos: recursos, bem intelectual e bem comum no espectro da ciência. 
Conceitualmente, os recursos englobam componentes (naturais, ecológicos, ambientais, entre outros) dispostos na natureza e à disposição de uma coletividade. Os bens intelectuais são produtos resultantes de processos criativos, inovadores, culturais e científicos oriundos de um processamento de conhecimento cognitivo. E por bem comum, entende-se a junção de recursos naturais e de bens intelectuais disponíveis e acessíveis em prol do desenvolvimento econômico, tecnológico, científico e cultural à sociedade em geral.

Explica Herscovici (2013, p. 18, grifo nosso) que "bem comum, em determinada coletividade (componentes ecológicos, recursos naturais, conhecimento comum, etc.), e a apropriação privada de tais bens, pode ser prejudicial para a comunidade e se traduzir pelo esgotamento do estoque disponível". Portanto, o questionamento se fundamenta entre, a apropriação dos bens comuns regidos por DPIs, e o acesso aberto dos mesmos, em prol de uma determinada coletividade e em consonância com os princípios norteadores da ciência aberta. Alarga-se esse escopo para o entendimento dos bens intelectuais, como bens comuns e portanto, compreendidos também, como direitos difusos e coletivos. $\mathrm{O}$ acesso aos bens intelectuais procedentes da própria ecologia social caminha para uma cultura colaborativa e compartilhada.

Nessa cultura, a economia criativa e a ciência do commons são transversais, e conduz às novas práticas com espaços interativos e colaborativos que promovam a inovação, a criatividade e saberes (científicos, artísticos, culturais e sociais), visando o bem-estar e a sustentabilidade dos recursos comuns.

Albagli (2015) e Krokoscz (2015) reforçam essa ideia, no que diz respeito ao escopo da ciência, para o paradigma subjacente do commons e da cultura do bem intelectual, como um recurso comum. Tal paradigma está baseado em práticas relacionadas com a autoria colaborativa, por meio de produtos originados de co-criações e co-colaborações, bem como, dos processos de inovação aberta, produções peer-to-peer, wiki, crowdsourcing, entre outras, reforçando a noção emergente da cultura colaborativa e do compartilhamento na perspectiva da ciência do commons.

Os DPIs regidos pela propriedade privada dos bens comuns (intelectuais e recursos naturais) são reconfigurados para a cultura do comum. É o fenômeno entendido pela 'não propertising', termo cunhado pelos defensores da Teoria do Commons, que refere-se a não proprietização dos bens comuns. A nova acepção é conduzida para o compartilhamento, o acesso e uso desses bens comum na cultura do commons. 
Os bens comuns nos atuais sistemas de DPIs vigentes, são regulados com a intervenção do Poder Estatal. Alguns estudiosos afirmam que a ausência do Estado como ente regulador é necessário para evitar que haja o uso indiscriminado (recursos naturais e bens intelectuais) e a escassez irreversível desses bens (FROSIO, 2014). A escassez dos bens comuns, especialmente os recursos naturais, é chamada de tragédia do commons.

No que diz respeito aos bens intelectuais a "open science no que se refere aos DPIs foi corroída pela propertising implacável de direitos intelectuais" (FROSIO, 2014, p. 7, tradução nossa). Entende-se por propertising a apropriação privada e exclusiva dos bens intelectuais, que mantém-se até os dias atuais, em virtude da indústria editorial e a iniciativa privada regentes dos mercados de conhecimento e informação, manterem o controle dos DPIs, com o reforço dos códigos jurídicos. Tais discussões estão assentadas na segunda vertente relacionada ao commons.

O movimento da ciência aberta tem avançado com o surgimento de "mecanismos regulatórios visando reverter assimetrias resultantes da apropriação e distribuição privada dos conhecimentos, sobretudo em áreas sensíveis e com forte apelo social, como saúde, agricultura, alimentação e meio ambiente" (ALBAGLI, 2015, p. 18). Esta é uma acepção generalista da noção do commons. É a ideia preliminar de uma ciência do 'comum', que pressupõe o encapsulamento dos dados de pesquisa como bens intelectuais, público e comum na ciência aberta.

A Teoria do Commons originada na corrente denominada Commons Paradigms foi teorizada por Ostrom (1990). É o marco teórico no contexto da governança econômica dos recursos intelectuais e naturais e levanta questionamentos acerca da proprietização desses bens de acesso comum. A teoria demonstra que as pessoas comuns são capazes de criar regras e instituições que permitem a gestão sustentável e equitativa dos recursos compartilhados.

Pressuposto essencial da ciência do comum que busca na sustentabilidade e no compartilhamento de bens comuns, benefícios para uma determinada coletividade. Krokoscz (2015) e Nielsen (2011) afirmam que a ideia do paradigma do commons no que se refere aos conhecimentos científicos estão sendo compartilhados, abertamente, desde o processo de descoberta (dados de pesquisa) por cientistas, ambientalistas, usuários da internet e outros envolvidos na cultura da ciência do comum. Essa é a nova postura da cultura colaborativa e do compartilhamento. Visa que as novas práticas e espaços interativos e colaborativos promovam a criatividade, inovação e saberes científicos, artísticos e culturais. 
Diferentes formas de economia solidária e colaborativa apresentam eficiência social na economia digital quando "os sistemas dos commons baseados sobre o compartilhamento de informações e de bens culturais são social e economicamente mais eficientes que os sistemas baseados sobre a propriedade privada e sobre a distribuição a partir de suportes materiais individualizados" (HERSCOVICI, 2013, p. 190, tradução nossa).

É neste contexto que os DPIs entram no embate, pois de um lado estão os modelos tradicionais arraigados no paradigma proprietário econômico e na cultura do copyright e das patentes, e do outro, a busca pelo acesso livre dos bens intelectuais e culturais por meio do viés aberto e público, visto que:

A propriedade privada e suas consequências econômicas e jurídicas vão de encontro à tendência de compartilhar, de co criação e inovação; a regulação ao livre acesso; a vontade de manter determinado bem ou produto em estado de escassez, incluindo-a valor, contrasta com a abundância e a capacidade de renovação de recursos na Economia Criativa - recursos estes, em sua maioria, culturais e intelectuais [...]. (CARVALHO et al., 2015, p. 180).

O conhecimento é um bem intelectual cujo entendimento se apoia como um bem intangível, sendo assim: "conhecimento é diferente. Um produto hoje se torna viável e útil pelo conhecimento incorporado (pesquisa, design, comunicação etc., os chamados bens intangíveis) do que pela matéria-prima e trabalho físico" (DOWBOR, 2015, p. 2).

É assim, um ativo intangível incorpóreo, que necessita ser incorporado e encapsulado para ganhar forma, adquirindo um status de bem intelectual e, consequentemente, com direitos associados. O conhecimento em si mesmo não é um bem intelectual tangível, precisa ganhar forma, por meio de um processo de trabalho científico ou criativo. É por meio da incorporação e apreensão do saber, que os recursos inovadores, oriundos dos labores intelectuais, criativos, artísticos e culturais resultam em produtos culturais e intelectuais que por natureza são públicos.

Todavia, há de se considerar que os processos exploratórios nas searas científica, econômica, cultural e industrial são conduzidos, na maioria das vezes, por mercados capitalistas que regem a exploração comercial da Pl. Bens comuns resultantes dos processos científicos, inovativos e criativos rendem-se fatalmente aos apelos econômicos do mercado (GATTI; CORTIZ; DOWBOR, 2014).

Nesse sentido, um dos questionamentos é direcionado à regulação dos bens comuns por mecanismos e instrumentos que envolvem a Pl. Pressupõe-se que os bens comuns promovem a sustentabilidade econômica por meio de processos inovadores, criativos, 
intelectuais e culturais para uma determinada coletividade, além de impulsionar soluções e crescimento social, econômico e científico sem restrições ao acesso e usufruto dos mesmos.

Trazendo para o contexto da ciência aberta almeja-se que o acesso aberto e público também abranja os dados de pesquisa. Assim, os dados de pesquisa passam a ser revestidos na classificação de bem comum. Nesse sentido, os bens intelectuais comuns devem estar acessíveis, contudo há de se considerar os aspectos relacionados com a tipologia (observacionais, experimentais e computacionais), a natureza (científica, governamental, cultural, artística) e o acesso (aberto, fechado, restrito, embargado). Muito embora, ainda prevaleça questões relacionadas aos sistemas autorais vigentes, sendo os bens intelectuais comuns estão sendo configurados no contexto da ciência aberta.

Além do commons outro destaque dessa vertente é a Economia Criativa (EC). A EC é um conceito inovador e não usual no contexto da ciência tradicional. No Direito a EC é um locus de interseção com a propriedade intelectual e possui características que buscam a valorização de produtos inovadores, culturais e intelectuais, a dinamicidade de seus processos e a tendência do compartilhamento (CARVALHO et al., 2015).

Os primeiros estudos sobre os processos criativos tiveram início a partir do fim do predomínio da economia pautada na segunda Revolução Industrial, que abriu novos espaços para uma dinâmica denominada de Economia Criativa. Analogamente, a mudança de paradigma - associada à teoria de Thomas Kuhn na obra 'A Estrutura das Revoluções' - que traz o paradigma proprietário intelectual para o compartilhamento de bens intelectuais e culturais oriundos de processos criativos.

A EC tem está sustentada no tripé: conhecimento, informação e inovação criativa. Esse tripé delineia as atividades que requerem conhecimento, informação (como ferramentas para a criatividade) e inovação que se dá através de novos aparatos tecnológicos e com os novos modelos de negócios (CARVALHO et al., 2015). Apesar da Economia Criativa ser oriunda do conceito gerado na seara econômica, e portanto, sustentada no paradigma proprietário, tem seu cerne na inovação e no compartilhamento.

Carvalho et al. (2015) afirmam que a natureza da EC direciona para que as atividades ligadas à valorização e à comercialização de produtos intelectuais, tecnológicos e culturais se tornem atividades dinâmicas, fluidas, empreendedoras e compartilhadas. Enquanto que, na visão de Howkins (2013) a EC tem sua base na criatividade. O autor afirma que a criatividade isolada não configura uma atividade econômica, mas quando ideias são associadas e se tornam um produto criativo (bem ou serviço), passam a ter implicações e valor econômicos. 
Howkins (2013), em seus estudos, traçou um limite cronológico para situar o estudo da criatividade por meio de cinco gerações demonstrado no Quadro 1.

\section{Quadro 1 - As cinco gerações do estudo da criatividade}

\begin{tabular}{|c|c|c|c|}
\hline Geração & Denominação & Ênfase & Época \\
\hline $\begin{array}{c}1^{a} . \\
\text { Geração }\end{array}$ & Pensamento criativo & Desenvolvimento de habilidades & $\begin{array}{l}\text { Década de } \\
1950\end{array}$ \\
\hline $\begin{array}{c}2^{\mathrm{a}} \text {. } \\
\text { Geração }\end{array}$ & $\begin{array}{l}\text { Solução criativa de } \\
\text { problemas }\end{array}$ & Produtividade e competitividade & $\begin{array}{l}\text { Década de } \\
1960\end{array}$ \\
\hline $\begin{array}{c}3^{\mathrm{a}} . \\
\text { Geração }\end{array}$ & O viver criativo & Autotransformação & $\begin{array}{c}\text { Década de } \\
1980\end{array}$ \\
\hline $\begin{array}{c}4^{\mathrm{a}} . \\
\text { Geração }\end{array}$ & $\begin{array}{l}\text { Criatividade como } \\
\text { valor social }\end{array}$ & $\begin{array}{c}\text { Solução de problemas sociais, aberta à } \\
\text { vida, à juventude, ao cotidiano }\end{array}$ & $\begin{array}{l}\text { Década de } \\
1990\end{array}$ \\
\hline $\begin{array}{c}5^{\mathrm{a}} . \\
\text { Geração }\end{array}$ & Economia criativa & $\begin{array}{l}\text { Geração e exploração da propriedade } \\
\text { intelectual }\end{array}$ & $\begin{array}{l}\text { Década de } \\
2000\end{array}$ \\
\hline
\end{tabular}

Fonte: Machado (2015, p. 40) baseado em Howkins (2013).

O entendimento desta divisão é baseado em uma trajetória de gerações. A $1^{\text {a }}$ geração centrada no pensamento criativo e no desenvolvimento de comportamentos técnicoespecializados. A $2^{a}$ geração buscou a solução criativa de problemas, baseada na produtividade e competitividade, no auge da Revolução Industrial da década de 1960. A $3^{a}$ geração desabrochou na década de 1980, na autotransformação, com os estudos e as pesquisas sobre a criatividade que estavam mais voltados para a dimensão individual. A $4^{\text {a }}$ geração se abre para uma busca mais ampla por soluções baseadas nas questões sociais, sustentabilidade e para a formulação de políticas públicas. E por fim, a $5^{a}$ geração baseada na economia criativa e na exploração da propriedade intelectual a partir da década de 2000. O estudo de um lado reflete a exploração econômica dos produtos criativos, do outro enfatiza o compartilhamento de bens intelectuais, prevalecendo o espírito inovador e colaborativo.

A ruptura com os modelos tradicionais de negócios (econômicos, educacionais, científicos) abre espaços para essas dinâmicas. Apesar dos produtos criativos estarem encapsulados por DPIs, eles são bens intelectuais que promovem a inovação e a cultura e, portanto, pressupõem serem acessíveis, públicos e gratuitos. No entendimento de Carvalho et al. (2015, p. 178) a "Economia Criativa parece rimar ainda com as ideias como as de 
conectividade, interação, compartilhamento, inovação; relaciona-se às novas mídias, novas tecnologias, ao empreendedorismo e à mudança de padrões".

No que concerne à ciência, os bens intangíveis estão associados a diferentes recursos, desde os bens intelectuais (renováveis), a exemplo do conhecimento, até os recursos naturais (escassos), classificados como bens comuns. Os recursos intangíveis se manifestam através da cultura, conhecimento e experiência são infinitos e renováveis e representam uma economia em abundância baseada nos modelos de colaboração (CARVALHO et al., 2015).

Nesse ponto converge o maior desafio da ciência aberta que é transformar recursos intangíveis e bens intelectuais, em bens comuns e públicos. A cultura do comum e do compartilhamento fortalecem a "busca de uma ciência aberta, colaborativa e conectada, uma reflexão sobre os desafios da propriedade intelectual e o direito à informação, e as implicações para relações de trabalho colaborativo e compartilhado na construção do conhecimento" (DOWBOR et al., 2015, p. 9).

A confluência da Economia Criativa com a ciência aberta está no contexto de bens intelectuais intangíveis, como por exemplo: o conhecimento. A colaboração e o acesso são necessários e vitais "para a sobrevivência de todos, o acesso às tecnologias que reduzem o impacto climático, por exemplo, não só não deve ser travado por patentes, como fomentado" (DOWBOR, 2011, p. 3).

Tal reflexão se fundamenta em dois entendimentos: o primeiro relaciona-se ao argumento de que as pesquisas financiadas com recursos públicos deverão produzir resultados científicos que tragam melhoria, bem-estar, sustentabilidade e desenvolvimento à sociedade. Tais pesquisas produzem diversos produtos que pressupõem a geração de bens intelectuais, acessíveis, abertos, públicos e gratuitos.

Esse entendimento pressupõe dois pontos de vista: o primeiro, são os direitos proprietários vigentes e garantidos por lei, para autores, pesquisadores, artistas e inventores, que por séculos foram institucionalizados em um modelo econômico tradicional, que versa pela individualidade, exclusividade e originalidade; o segundo está na defesa da produção que exploram as ideias de justiça ambiental, no sentido econômico-sócio-cultural com novas vertentes de capitalização do intelectual pautado nesse paradigma econômico.

Assim, eliminar as práticas atuais que aumentam a segregação e estimulam o monopólio social e econômico se faz imperativo (ALBAGLI, 2015). As implicações no tocante aos DPIs constituem um dos gargalos da ciência aberta e provoca novas reflexões acerca dos sistemas atuais vigentes em cada país. É sabido que não é um movimento fácil e rápido de 
acontecer. O monopólio editorial ainda é um sistema paralelo que rege mundialmente o mercado de informação. O movimento de acesso aberto trouxe novas formas de suportes informacionais, contudo o modus operandi de fazer a ciência tradicional ainda está vigente.

\section{CONCLUSÃO}

A reflexão final deste artigo direciona para o repensar dos direitos de propriedade intelectual - de um paradigma proprietário - para um espaço de processos colaborativos e compartilhados. Os DPIs no contexto da ciência aberta estão sendo repensados sob o olhar da Economia Criativa e da Ciência do Commons. A EC é o espaço alternativo, inovador e colaborativo que absorve os recursos naturais e os bens intelectuais como produtos primários e dão sustentabilidade ao desenvolvimento e à promoção de políticas públicas para a ciência aberta. É a partir da EC que o processo de inovação emergido de ambientes inovadores, científicos e criativos são acomodados na essência do commons como bens comuns, e para tanto, são de natureza aberta, pública e gratuita.

No que tange as questões que envolvem a autoria no cerne dos DPIs esta caminha para uma nova forma de reconhecimento autoral, por meio da atribuição e da citação. Especialmente, nos produtos intelectuais advindos da pesquisa científica aberta. Os dados de pesquisa são bens intelectuais comuns, cuja autoria é atribuída proporcionalmente a todos os envolvidos no projeto de pesquisa. Assim, os sistemas de DPIs precisam ser redirecionados para a nova modalidade de autoria colaborativa.

Grande desafio político-ético-legal está em conduzir uma agenda global para o entendimento da ciência aberta e o rompimento de paradigmas existentes na práxis científica. A ciência aberta vislumbra a criação, melhoria e sustentabilidade de áreas sensíveis como, saúde, meio ambiente, alimentação, agricultura, segurança nacional, educação e pesquisa e busca fomentar o desenvolvimento econômico, científico e tecnológico do país.

A necessidade da promoção da ciência que supere a proprietização, baseada no modelo econômico tradicional e sistemas legais vigentes para o contexto da ciência aberta é um movimento irreversível e ascendente em prol do acesso aberto aos bens intelectuais. 


\section{REFERÊNCIAS}

ALBAGLI, S. Ciência aberta em questão. In: ALBAGLI, S.; MACIEL, M. L.; ABDO, A. H. (Org.). Ciência aberta, questões abertas. Brasília: IBICT; Rio de Janeiro: UNIRIO, 2015. Disponível em: <https://www.cienciaaberta.net/ciencia-aberta-questoes-abertas-o-livro/>. Acesso em: 19 set. 2016.

BORGMAN, C. L. From Gutenberg to the Global Information Infrastructure: Access to Information in the Networked World. London: MIT Press, 2003. Disponível em: $<$ https://mitpress.mit.edu/books/gutenberg-global-information-infrastructure>. Acesso em: 19 abr. 2016.

BRAMAN, S. Defining Information Policy. Journal of Information Policy, v. 1, n. 1, p. 1-5, 2011. Disponível em: <http://pantherfile.uwm.edu/braman/www/html/pub.html>. Disponível em: 12 set. 2015.

BRUYNE, P.; HERMAN, J.; DE SCHOUTHEETE, M. Dinâmica da pesquisa em ciências sociais: os pólos da prática metodológica. Tradução de Ruth Joffily. Rio de Janeiro: Francisco Alves, 1977.

BUFREM, L. S. Configurações da pesquisa em ciência da informação, DataGramaZero: Revista de Informação, v. 14, n. 6, p. 1-15, dez. 2013.

CARVALHO, V. M. B.; LANZILLO, A. S. S.; GUIMARÃES, P. B. V. A Economia Criativa: Conceito e Relação com o Direito. FIDES, Natal, v. 6, n. 1, jan./jun. 2015. Disponível em: <http://www.cidp.pt/publicacoes/revistas/rjlb/2015/3/2015_03_1493_1510.pdf>. Acesso em: 21 fev. 2016.

DELFANTI, A.; PITRELLI, N. Ciência aberta: revolução ou continuidade? In: ALBAGLI, S.; MACIEL, M. L.; ABDO, A. H. (Org.). Ciência aberta, questões abertas. Brasília: IBICT; Rio de Janeiro: UNIRIO, 2015.

DOWBOR, L. O sistema financeiro atual trava o desenvolvimento econômico. Estud.av., São Paulo , v. 29, n. 83, p. 263-278, abr. 2015. Disponível em 
<http://www.scielo.br/scielo.php?script=sci_arttext\&pid=S0103-

40142015000100263\&lng=pt\&nrm=iso>. Acesso em: 29 nov. 2015. http://dx.doi.org/10.1590/\$0103-40142015000100013

EISENSTEIN, E. L. A Revolução da Cultura Impressa: os Primórdios da Europa Moderna. Tradução de The Printing Revolution in Early Modern Europe. São Paulo: Ática, 1998. Disponível em: <http://sapereaude10.blogspot.com.br/2013/05/a-revolucao-da-cultura-impressa-de.html>. Acesso em: 25 maio 2016.

FROSIO, G. F. Open Access Publishing: A Literature Review. Reino Unido: Research Fellow School of Law University of Nottingham, UK, 2014. Disponível em: $<$ http://www.create.ac.uk/publications/open-access-publishing-a-literature-review/>. Acesso em: 8 out. 2016.

GATTI, D.; CORTIZ, D., DOWBOR, L. Em busca de uma ciência aberta, colaborativa e conectada. In: DOWBOR, L.; SILVA, H. (Org.). Propriedade intelectual e direito à informação. São Paulo: EDUC, 2014. Disponível em: <http://dowbor.org/blog/wpcontent/uploads/2013/03/14Livro_Propriedade-intelectual.pdf>. Acesso em: 16 ago. 2016.

GRAY, J. eScience: a transformed scientific method. In: HEY, T.; TANSLEY, S.; TOLLE, K. (Ed.). The Fourth Paradigm: Data-Intensive Scientific Discovery. Redmond, Washington. UNT Digital Library. Palestra de Jim Gray em 11 de janeiro de 2007, cedida a NRC-CSTB 1, em Mountain View, CA. Disponível em: <http://digital.library.unt.edu/ark:/67531/metadc31516/>. Acesso em: 25 abr. 2016.

HERSCOVICI, A. Escolha coletiva, governança e direitos de propriedade: uma análise econômica dos commons. Nova econ., Belo Horizonte, v. 23, n. 1, p. 185-208, 2013. Disponível em: $<$ http://www.scielo.br/scielo.php?script=sci_arttext\&pid=S010363512013000100007\&lng=pt\&nrm=iso\&tlng=en>. Acesso em: 19 abr. 2016.

HOWKINS, John. Economia criativa: como ganhar dinheiro com ideias criativas. Tradução de Ariovaldo Griesi. São Paulo: M. Books, 2013. 
KROKOSCZ, M. Outras palavras sobre autoria e plágio. São Paulo: Atlas, 2014.

MARQUES, Lilian Emanueli; PINHEIRO, Marta Macêdo Kerr. A cúpula mundial sobre a sociedade da informação: foco nas políticas de informação. Inf. \& Soc.:Est., João Pessoa, v.23, n.1, p. 117131, jan./abr. $2013 . \quad$ Disponível em: <http://www.ies.ufpb.br/ojs/index.php/ies/article/download/15450/9536>. Acesso em: 21set.2016.

MARTINS FILHO, P. Direitos autorais na Internet. Ci. Inf., Brasília, v. 27, n. 2, 1998. Disponível em: <http://www.scielo.br/scielo.php?script=sci_arttext\&pid=S0100-19651998000200011>. Acesso em: 22 maio 2015

NIELSEN, M. A. Reinventing discovery: the new era of networked science. Princeton, N.J: Princeton University Press, 2011.

NOGUEIRA, R. H.; GUIMARÃES, P. B. V.; XAVIER, Y. M. de A. Desenvolvimento e economia criativa: uma análise preliminar das origens sichépe rumos da economia criativa e sua repercussão no direito. In: GUIMARÃES, P. B. V.; XAVIER, Y. M. de A. (Org.). O Direito da Economia Criativa: Temas de Desenvolvimento e Propriedade Intelectual. São Paulo: Editora Max Limonad, 2015.

OLIVEIRA, A. C. S. de; SILVA, E. M. Ciência Aberta: dimensões para um novo fazer científico. Informação \& Informação, Londrina, 2016. No prelo. Disponível em: <http://www.uel.br/revistas/uel/index.php/informacao/issue/view/1143>. Acesso em: 20 set. 2016.

OSTROM, E. Governing the Commons: the evolution of institutions for collective action. Cambridge: Cambridge University Press, 1990.

PAESANI, Liliana Minardi. Direito e Internet: Liberdade de informação, privacidade e responsabilidade civil. 5.ed. Rio de Janeiro: Atlas, 2012. 
Revista de Direito da Cidade

vol. 11, no 1. ISSN 2317-7721

DOI: $10.12957 /$ rdc.2019.32031

Trabalho enviado em 26 de dezembro de 2017

Aceito em 07 de abril de 2018 